\title{
Performance Characteristic of the $\beta$-Human Chorionic Gonadotropin Assay on the Access 2 for Its Use in Doping Control
}

\author{
Min-Jung Kang, ${ }^{*}$ Hyeim Lee, ${ }^{\dagger}$ Sang Mi Shin, ${ }^{\dagger}$ Hye Hyun Yoo, ${ }^{\ddagger}$ Oh-Seung Kwon, ${ }^{\dagger}$ Changbae Jin, and Bong Chul Chung \\ Integrated Omics Center, Korea Institute of Science and Technology, Hawolgokdong 39-1, Seoul 130-650, Korea \\ *E-mail:mjkang1@kist.re.kr \\ ${ }^{\dagger}$ Doping control center, Korea Institute of Science and Technology, Hawolgokdong 39-1, Seoul 130-650, Korea \\ ${ }^{\ddagger}$ Department of Pharmacy, College of Pharmacy, Hanyang University, Ansan, Gyeonggi-do 426-791, Korea \\ Received July 21, 2010, Accepted August 23, 2010
}

\begin{abstract}
The objective of this study was to validate performance characteristics of the Access 2 (Beckman coulter) system for hCG assays for use as a confirmation test for doping control. The Access 2 assay was linear up to $500 \mathrm{IU} / \mathrm{L}$. The correlation coefficient was higher than 0.999 , and the sensitivity of the linearity was 0.82 . There were no false positive or false negative cases. LOD was $0.59 \mathrm{IU} / \mathrm{L}$. The method was robust when performed by different people. Repeatability and reproducibility were below 7\%. We compared reproducibility and recoveries of Access 2 and Elecsys 2010. Access 2 demonstrated higher reproducibility than Elecsys 2010. Recoveries (accuracy) of Access 2 were between 85 and 105\%. Recoveries for Elecsys 2010 were between 91 and 104\%.
\end{abstract}

Key Words: $\beta$-hCG, Access 2, Doping control, Method evaluation, Confirmation method

\section{Introduction}

Human chorionic gonadotropin (hCG) is a glycoprotein composed of two subunits, $\alpha$ and $\beta$, which are non-covalently joined (1). It is produced at high concentrations by trophoblasts of the placenta (2). hCG is known to stimulate production of testosterone in the testicles of males. Therefore, male athletes abuse preparations of hCG in order to increase testosterone production, particularly after prolonged use of anabolic steroids. In doping control analysis, the presence of a high amount of hCG in male athletes often provides a clue to detection of anabolic steroid abuse $(3,4)$. Measurement of hCG in urine is used in detection of illegal steroid abuse use in male athletes. However, in urine, many different kinds of hCG exist such as intact hCG, intact hCG dimer, free hCG- $\beta$ subunits, free hCG- $\alpha$ subunits, $\beta$-core fragment, nicked hCG, and a carboxyl terminal peptide fragment. Therefore, measurement of hCG in urine is varied on different antibodies and instruments. Discussion about the cut-off values didn't give clear results yet. Cut-off values between 10 and $25 \mathrm{IU} / \mathrm{L}$ during ten years have been suggested by Cowan et al. $(5,6,7)$. In 1998, Delbeke et al. suggested 5 IU/L as a decision limit (8). Since February 2004, the technical document of the World Anti-Doping Agency (WADA) has stated that an hCG assay should have a minimum required performance limit (MRPL) of at least $5 \mathrm{IU} / \mathrm{L}(9)$, however, there is no decision limit suggested which has presented us with a challenge.

Moreover, according to recommendations by WADA, hCG analysis should employ two different antibodies recognizing different epitopes of hCG. In 2007, we validated IMx and Elecsys 2010 using urine samples (11), and we have employed the Elecsys 2010 for screening and IMx for confirmation. Unfortunately, however, production of the IMx assay kit was discontinued. Therefore, a new analytical system for confirmation analysis of hCG was needed. Most commercial instruments for the hCG assay had been validated using serum samples. Few commercial hCG assays have thus far been validated for urine screening
(10). In this study, the analytical performance characteristic of the Access 2 system was investigated, and precision and accuracy were compared with that of Elecsys 2010 for urinary hCG assays. More than 10000 athlete samples were analyzed to suggest the decision limit for anti doping purposes.

\section{Materials and Methods}

Calibration and linearity. Sigma standard for $\beta$-hCG was diluted using negative human male urine (with no endogenous $\beta$-hCG). The negative urine was filtered. Standard calibration concentrations were 500, 150, 25, 10, 5, and $1 \mathrm{IU} / \mathrm{L}$. The spiked urine samples were aliquot into sample cups, and $\beta$-hCG concentrations were measured using the Access 2 system (Beckman Coulter, Inc., Fullerton, USA). The calibration curve was drawn using these spiked urine samples and regression coefficient was calculated using Excel.

Sensitivity. Sensitivity, which is defined as the average slope on different days, was measured on 6 different concentration standards for four different days. After linear regression of each calibration curve, the average of the slope was calculated. The CV (\%) was also calculated.

Selectivity. Selectivity was checked for 20 negative control urine samples (NCU) and 10 positive control urine samples (PCU).

Repeatability and reproducibility. Repeatability (within day precision) was determined via measurement of the concentrations of two spiked urine samples in four repetitions on the same day, whereas reproducibility (between days precision) was determined by running these two spiked urine samples on four different days. Both Access 2 and Elecsys 2010 were used for measurement of precision.

Recovery. Both Access 2 and Elecsys 2010 were used for measurement of recovery (accuracy). Recoveries were determined via measurement of the two spiked urine samples in three repetitions on three different days. Percentage recovery 
of $\beta$-hCG was calculated in accordance with the following equation:

$\%$ Recovery $=$ Value obtained/Amount added $\times 100 \%$

\section{Results and Discussion}

Calibration and linearity. The calibration curve is shown in Figure 1. With the exception of low $\beta$-hCG concentrations (1 and $5 \mathrm{IU} / \mathrm{L})$, the coefficient of variation $(\mathrm{CV})$ was below $10 \%$. The correlation coefficient was higher than 0.999 after linear regressions. The dynamic range was $1-500 \mathrm{IU} / \mathrm{L}$. Mean value of each spiked sample was lower than the nominal concentration. This might have been caused by a urine matrix effect.

Sensitivity. The four calibration sets were analyzed on four different days for calculation of sensitivity. The average slope was calculated for the sensitivity parameter $(0.82)$. The $\mathrm{CV}$ of four different days' slope was $7.43 \%$, meaning that the sensitivity of the analysis is robust.

Selectivity. Assuming that the cut off value for positivity is 5 IU/L, we have confirmed that our method has enough selectivity. The twenty negative control urine samples were tested to determine false positivity, and the measured value was $0.29 \pm$ 0.22 , with no false positive results. For observance of false negativity, 10 positive control urine samples (spiked urine samples with a concentration of $10 \mathrm{IU} / \mathrm{L}$ ) were tested. The measured value was $6.78 \pm 0.30$, with no false negative result.

Repeatability and reproducibility (precision). We compared repeatability (within day precision) and reproducibility (between

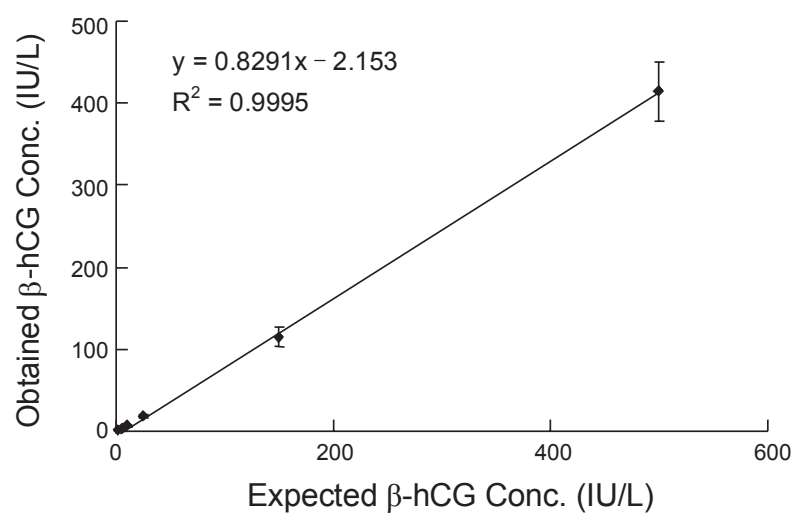

Figure 1. Calibration curve of the urinary $\beta$-hCG assay measured by Access 2 using standard spiked urine samples in the concentration range of $1-500 \mathrm{IU} / \mathrm{L}$.

Table 1. Sensitivity of the method was calculated from the $\% \mathrm{CV}$ of slope of calibration curves on different days

\begin{tabular}{ll}
\hline \multicolumn{2}{l}{ Calibration equation at different days } \\
\hline 1 set & $\mathrm{y}=0.829 \mathrm{x}-2.153$ \\
2 set & $\mathrm{y}=0.894 \mathrm{x}-3.082$ \\
3 set & $\mathrm{y}=0.752 \mathrm{x}+0.456$ \\
4 set & $\mathrm{y}=0.789 \mathrm{x}-2.493$ \\
Average of slope & 0.82 \\
SD of slope & 0.06 \\
$\%$ CV of slope & 7.43 \\
\hline
\end{tabular}

Table 2. Repeatability and reproducibility (precision) of the $\beta-\mathrm{hCG}$ assay on Access-2 and Elecsys2010 using spiked urine samples

\begin{tabular}{cccccc}
\hline & \multicolumn{2}{c}{$\begin{array}{c}\text { Measured by } \\
\text { Access-2 }\end{array}$} & & \multicolumn{2}{c}{$\begin{array}{c}\text { Measured by } \\
\text { Elecsys2010 }\end{array}$} \\
\cline { 2 - 3 } \cline { 5 - 6 } $\begin{array}{c}\text { Spiked urine } \\
\text { samples }\end{array}$ & $\begin{array}{c}\text { Between } \\
\text { run } \\
\text { CV }(\%)\end{array}$ & $\begin{array}{c}\text { Between } \\
\text { day } \\
\text { CV }(\%)\end{array}$ & & $\begin{array}{c}\text { Between } \\
\text { run } \\
\text { CV }(\%)\end{array}$ & $\begin{array}{c}\text { Between } \\
\text { day } \\
\text { CV (\%) }\end{array}$ \\
\hline QC1 $(10 \mathrm{mIU} / \mathrm{mL})$ & 4.36 & 4.17 & & 4.63 & 5.07 \\
QC2 $(20 \mathrm{mIU} / \mathrm{mL})$ & 3.34 & 1.35 & & 4.39 & 6.14 \\
\hline
\end{tabular}

Table 3. Recovery (accuracy) of $\beta$-hCG on Access- 2 and Elecsys 2010 using spiked urine samples

\begin{tabular}{|c|c|c|c|}
\hline \multirow[t]{2}{*}{ Days } & \multirow{2}{*}{$\begin{array}{l}\text { Spiked urine } \\
\text { samples }\end{array}$} & $\begin{array}{l}\text { Measured by } \\
\text { Access-2 }\end{array}$ & $\begin{array}{l}\text { Measured by } \\
\text { Elecsys } 2010\end{array}$ \\
\hline & & Recovery & Recovery \\
\hline \multirow{2}{*}{$1 \mathrm{st}$} & QC1 (10mIU/mL) & $104.6 \%$ & $103.6 \%$ \\
\hline & QC2 (20mIU/mL) & $88.6 \%$ & $100.6 \%$ \\
\hline \multirow{2}{*}{ 2nd } & QC1 (10mIU/mL) & $85.36 \%$ & $94.2 \%$ \\
\hline & QC2 (20mIU/mL) & $86.07 \%$ & $96.5 \%$ \\
\hline \multirow{2}{*}{$3 \mathrm{rd}$} & QC1 (10mIU/mL) & $108.6 \%$ & $92.1 \%$ \\
\hline & QC2 (20mIU/mL) & $100.4 \%$ & $91.5 \%$ \\
\hline \multirow{2}{*}{$\mathrm{CV}(\%)$} & QC1 (10mIU/mL) & 12.48 & 6.37 \\
\hline & QC2 (20mIU/mL) & 8.35 & 4.74 \\
\hline
\end{tabular}

day precision) for Access 2 and Elecsys 2010. The within and between day precision of Elecsys 2010 were below 7\%. Access 2 gave better precision than Elecsys 2010. Access 2 showed precision below 5\%. Precision results are shown in Table 2.

Recovery (accuracy). Recoveries (accuracy) are summarized in Table 3. In the case of Access 2, recoveries were between 85 and $105 \%$. For Elecsys 2010, recoveries were between 91 and $104 \%$. The CV for accuracy of Elecsys 2010 was below $13 \%$, and those of access 2 were below 7\%. Elecsys 2010 showed better accuracy than Access 2 .

LOD and LOQ. LOD and LOQ were determined according to NATA Guidelines-Technical note 17(12). After the lower

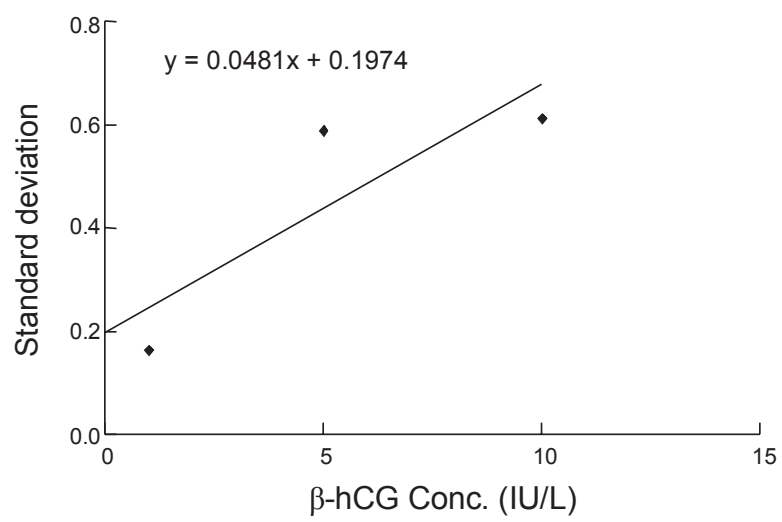

Figure 2. LOD was determined by extrapolation of the linear curve of SD (standard deviation). The Y-intercept was considered as $\mathrm{s}_{\sigma}$, and $3 \mathrm{~s}_{\sigma}$ was calculated as LOD. 


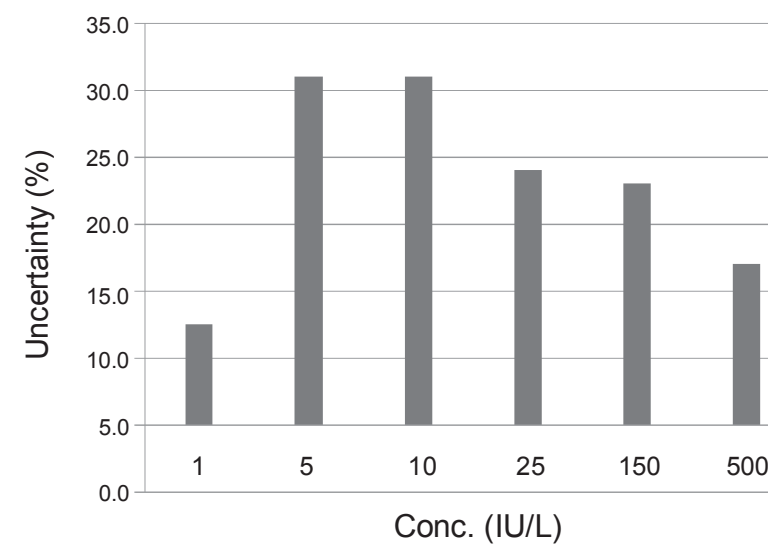

Figure 3. Uncertainty (\%) of $\beta$-hCG assay kit measured by Access 2 in the concentration range between 1 and $500 \mathrm{IU} / \mathrm{L}$.

concentration standards $(1,5,10 \mathrm{IU} / \mathrm{L})$ were analyzed, standard deviations (SD) of these concentrations were plotted against concentrations for calculation of the LOD (shown in Figure 2). By extrapolation of the linear curve, the y-intercept was calculated from the graph, and is considered as $\mathrm{s}_{\sigma}$. The $3 \mathrm{~s}_{\sigma}$ was calculated as LOD. LOQ was calculated as 3 LOD. LOD was $0.59 \mathrm{IU} / \mathrm{L}$, and LOQ was $1.78 \mathrm{IU} / \mathrm{L}$.

Ruggedness. During the first 2 days, the experiment was performed by Heyim Lee,. and on the third day, the experiment was performed by Min-Jung Kang. Results of the analysis satisfied FDA criteria of FDA written in "Guidance for Industry Bioanalytical method validation" stating that the $\mathrm{CV}$ for within day analysis should fall below $10 \%$, and the $\mathrm{CV}$ for between day analyses should be less than $15 \%$. The CV for Ruggedness was less than $5 \%$.

Uncertainty of $\boldsymbol{\beta}$-hCG assay kit measured by Access 2 . Figure 3 shows the calculated uncertainty of $\beta$-hCG assay kit measured by Access 2 in the concentration range of 1 and 500 $\mathrm{IU} / \mathrm{L}$. In the doping control analysis, uncertainty between 5 and 10 is very important because the suggested decision limit lay in this concentration range. However, the uncertainty of this range were highest (about $30 \%$ ) in the measured concentration range. It means that it is very difficult to decide positivity of $\mathrm{hCG}$ abuse. This result suggests that decision protocol should be carefully discussed. In case of $\mathrm{CV}$ for each concentration, $\mathrm{CV}$ values were increased as the concentration decreased. But the uncertainty of $1 \mathrm{IU} / \mathrm{L}$ was lowest among the measured concentrations. Uncertainty was calculated from the difference between measured amount and theoretical value. As it is shown in Figure 1, the slope of correlation is lower than 1 . The measured values are lower than theoretical values and the difference become larger as the concentrations increase. Both linearity and $\mathrm{CV}$ gave effect on uncertainty.

Comparison of Access 2 and Elecsys 2010. The same samples were measured using two different instruments. One sample was measured in triplicate at the same time, and three times on different days. The measured values by Access 2 were quite different from those by Elecsys 2010. It seems to be caused by different antibodies the assay kits employed. Linearity can be observed if the positive samples are excluded. The positive samples gave different concentration ratios comparative to preg-

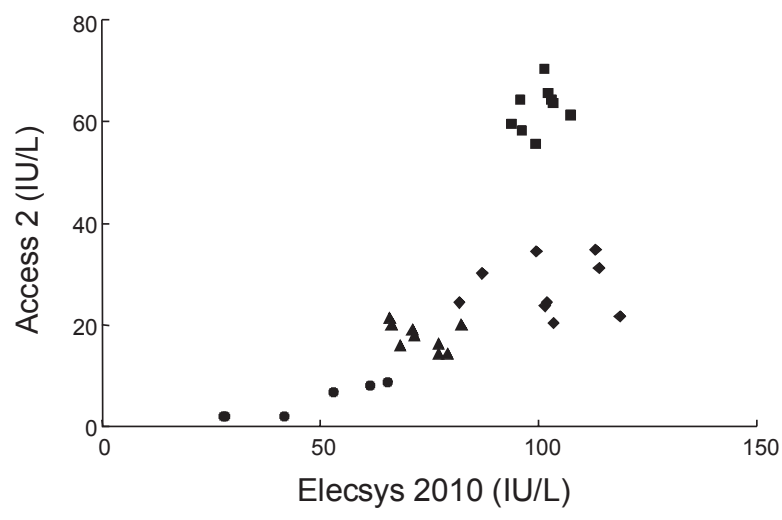

Figure 4. Comparison of the $\beta$-hCG concentration of positive sam-

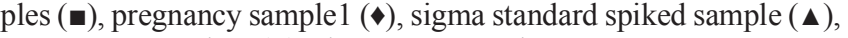
pregnancy sample $2(\bullet)$ Elecsys 2010 and Access 2.

nancy samples and sigma standard spiked samples. Two pregnancy samples and a sigma standard spiked sample gave a ratio of less than 0.5 when concentrations of $\beta-h C G$ measured by Access 2 were divided by those measured by Elecsys 2010 . Positive samples gave a ratio of more than 0.5 with the calculation of $\mathrm{C}_{\text {Access } 2} / \mathrm{C}_{\text {Elecsys2010. }}$. All concentrations of $\beta$-hCG measured by Access 2 were lower than those measured by Elecsys 2010. These results are shown in Figure 4.

The difference in concentrations measured by different instruments might be caused by affinity of antibodies employed by Elecsys 2010 and Access 2. The ratios for different samples might be caused by different detection specificity of antibodies employed by Elecsys 2010 and Access 2. From the manufacturer's manual, The antibody employed by Access 2 can detect intact hCG, free $\beta$ hCG subunit, nicked intact hCG, nicked free $\beta$ hCG subunit, hyperglycosylated hCG, and asialo hCG. The antibody employed by Elecsys 2010 can detect intact hCG, free $\beta h C G$ subunit, nicked forms of hCG, and $\beta$-core fragment. The main difference is Elecsys 2010 assay system detects $\beta$-core fragment. The results suggest that the metabolites or composition of hCG in human urine contain many percent of $\beta$-core fragment. Positive samples seem to contain less $\beta$-core fragment. Further study is needed in order to explain this phenomenon.

\section{Conclusions}

The $\beta$-hCG assay method was validated on Access 2 , and the results show that this method could be used as a confirmation method for $\beta$-hCG. The hCG assay processed by Access 2 showed better precision and poor accuracy compared with that of Elecsys 2010. More than 10000 samples were measured for $\beta$-hCG in our laboratory; all values for negative samples were below $5 \mathrm{IU} / \mathrm{L}$. Therefore, we suggest $5 \mathrm{IU} / \mathrm{L}$ as a decision limit for positivity.

\section{References}

1. Cole, L. A. Clin. Chem. 1997, 43, 2233.

2. Stenman, U. H.; Tiitinen, A.; Alfthan, H.; Valmu, L. Hum. Reprod. 2006, 12, 769.

3. Cowan, D. A.; Kicman, A. T.; Walker, C. J.; Wheeler, M. J. J. 
Endocrinol. 1991, 131, 147.

4. De Boer, D.; De Jong, E. G.; Van Rossum, J. M.; Maes, R. A. A. Int. J. Sports Med. 1991, 12, 46.

5. Kicman, A. T.; Brooks, R. V.; Cowan, D. A. Br. J. Sports Med. 1991, 25, 73

6. Laidler, P.; Cowan, D. A.; Hider, R. C.; Kicman, A. T. Clin. Chem. 1994, 40, 1306.

7. Gam, L. H.; Tham, S. Y.; Latiff, A. J. Chromatogr. B Analyst. Technol. Biomed. Life Sci. 2003, 792, 187.
8. Delbeke, F. T.; Van Eenoo, P.; De Backer, P. Int. J. Sports Med. 1998, 19, 287.

9. World Anti-doping Agency; http://www.wada-ama.org.

10. Stenman, U.-H.; Unkila-Kallio, L.; Korhonen, J.; Alfthan, H. Clin. Chem. 1997, 43, 1293.

11. Shahzad, K.; Kim, D.-H.; Kang, M.-J. Clin. Biochem. 2007, 40, 1259.

12. Guidelines for the validation and verification of chemical test methods, NATA Guidelines Technical note 17. 